\title{
Precipitation trends and variability from 1950 to 2000 in arid lands of Central Asia
}

\author{
XU Ligang ${ }^{1,2}$, ZHOU Hongfei $^{1^{*}}$, DU Li ${ }^{2}$, YAO Haijiao ${ }^{1}$, WANG Huaibo ${ }^{2}$ \\ ${ }^{1}$ Fukang National Field Scientific Observation and Research Station for Desert Ecosystems, Xinjiang Institute of Ecology and Geography, \\ Chinese Academy of Sciences, Urumqi 830011, China; \\ ${ }^{2}$ Scientific Research Institute of Water Conservancy of Ningxia, Yinchuan 750021, China
}

\begin{abstract}
Climate warming will cause differences in precipitation distribution and changes in hydrological cycle both at regional and global scales. Arid lands of Central Asia (ALCA), one of the largest arid regions at the middle latitudes in the world, is likely to be strongly influenced by climate warming. Understanding the precipitation variations in the past is an important prerequisite for predicting future precipitation trends and thus managing regional water resources in such an arid region. In this study, we used run theory, displacement, extreme deviation theory, precipitation concentration index $(\mathrm{PCl})$, Mann-Kendall rank correlation and climatic trend coefficient methods to analyze the precipitation in wet and dry years, changes in precipitation over multiple-time scales, variability of precipitation and its rate of change based on the monthly precipitation data during 1950-2000 from 344 meteorological stations in the ALCA. The occurrence probability of a single year with abundant precipitation was higher than that of a single year with less precipitation. The average duration of extreme drought in the entire area was 5 years, with an average annual water deficit of $34.6 \mathrm{~mm}$ (accounting for $11.2 \%$ of the average annual precipitation over the duration). The occurrence probability of a single wet year was slightly higher than that of a single dry year. The occurrence probability of more than 5 consecutive wet years was $5.8 \%$, while the occurrence probability of more than 5 consecutive dry years was $6.2 \%$. In the center of the study area, the distribution of precipitation was stable at an intra-annual timescale, with small changes at an inter-annual timescale. In the western part of the study area, the monthly variation of precipitation was high at an inter-annual timescale. There were clear seasonal changes in precipitation ( $\mathrm{PCl}=12-36)$ in the ALCA. Precipitation in spring and winter accounted for $37.7 \%$ and $24.4 \%$ of the annual precipitation, respectively. There was a significant inter-annual change in precipitation in the arid Northwest China (PCl=24-34). Annual precipitation increased significantly $(P=0.05)$ in $17.4 \%$ of all the meteorological stations over the study period. The probability of an increase in annual precipitation was $75.6 \%$, with this increase being significant $(P=0.05)$ at $34.0 \%$ of all the meteorological stations. The average increasing rate in annual precipitation was $3.9 \mathrm{~mm} / 10 \mathrm{a}(P=0.01)$ in the ALCA. There were significant increasing trends $(P=0.01)$ in precipitation in Kazakhstan, Kyrgyzstan and Tajikistan, with rates of 2.6, 3.1 and $3.7 \mathrm{~mm} / 10 \mathrm{a}$, respectively.
\end{abstract}

Keywords: arid lands of Central Asia; precipitation; stability; tendency; Mann-Kendall method

Citation: XU Ligang, ZHOU Hongfei, DU Li, YAO Haijiao, WANG Huaibo. 2015. Precipitation trends and variability from 1950 to 2000 in arid lands of Central Asia. Journal of Arid Land, 7(4): 514-526. doi: 10.1007/s40333-015-0045-9

Global warming has become an indisputable fact (IPCC, 2007). The spatio-temporal distribution of precipitation and its trends and variability, associated with climate change caused by global warming and human activities, has received much attention, particularly in arid and semi-arid areas where precipitation is an extremely important environmental factor. In these areas, the distribution and variation of precipitation can have a significant impact on the local ecological systems and environment (Lioubimtseva et al., 2005; Lioubimtseva and Henebry, 2009). Precipitation in arid lands of Central Asia (ALCA) is largely influenced by westerly circulation and the North Atlantic Oscillation, especially in winter and spring (Rogers and Van

\footnotetext{
${ }^{*}$ Corresponding author: ZHOU Hongfei (E-mail: zhouhf@ms.xjb.ac.cn) Received 2014-10-31; revised 2015-01-26; accepted 2015-02-03

(c) Xinjiang Institute of Ecology and Geography, Chinese Academy of Sciences, Science Press and Springer-Verlag Berlin Heidelberg 2015
} 
Loon, 1979; Aizen et al., 2001). Chen et al. (2009) proposed the concept of "westerly mode" to describe the climate changes controlled by westerly circulation in Central Asia. Lioubimtseva and Henebry (2009) and Hedi et al. (2011) confirmed that precipitation in the western part of Central Asia displayed a continuous variation gradient, over which the annual precipitation tended to increase slightly. Temporal rainfall-NDVI response patterns show a temporal lag (1-3 months) between precipitation anomalies and vegetation activity (Ursula, 2013). In the desert area of North China, although precipitation is expected to increase in spring and summer and gradually decrease in winter, the annual precipitation is expected to rise (Xu et al., 2010). The probability of precipitation increasing in the extremely arid and arid areas of North China was $83 \%$ and $70 \%$, respectively (Wang et al., 2013a). The largest 5-day precipitation, average precipitation concentration index (PCI) and daily precipitation in the Tianshan Mountains of Central Asia have risen rapidly at the rates of 1.18, 0.09 and 6.75 $\mathrm{mm} / 10 \mathrm{a}$, respectively (Wang et al., 2013b). Further, results of most models have suggested that precipitation in the Qinghai-Tibetan Plateau will increase (Wang et al., 2008; Xu et al., 2008; Li et al., 2013). ALCA is different from other arid areas in the world because of its diverse landscapes with high mountains and basins. Precipitation in the mountain areas is relatively abundant, which provides water resources to the surrounding arid areas by means of runoff, while precipitation in the basin areas is scarce (Chen et al., 2011). Due to global warming, great changes in precipitation have occurred in the ALCA, which have had significant impacts on local industrial and agricultural production. Therefore, studies on pre- cipitation in the ALCA and its trends and variability in the future are of practical and theoretical significance.

\section{Materials and methods}

\subsection{Study area and data analysis}

The study area covered Kazakhstan, Uzbekistan, Turkmenistan, Kyrgyzstan, Tajikistan and the arid Northwest China (ANWC; ANWC includes Xinjiang, northern Qinghai, Hexi Corridor in Gansu and western Inner Mongolia; Fig. 1). As the hinterland of Eurasia, the study area lies between $46^{\circ} 30^{\prime}-96^{\circ} 22^{\prime} \mathrm{E}$ and $34^{\circ} 20^{\prime}-55^{\circ} 26^{\prime} \mathrm{N}$, and has a total area of $563.8 \times 10^{4} \mathrm{~km}^{2}$, accounting for one third of the entire arid land in the world. As a typical inland arid area, the fragile ecosystem and environment in the study area is sensitive to climate change. Most of the study area is desert, semi-desert and grassland, and therefore precipitation is essential to the local environment and ecological systems. There are 344 meteorological stations in the ALCA with 47 stations in Kazakhstan, 53 in Kyrgyzstan, 40 in Tajikistan, 14 in Turkmenistan, 95 in Uzbekistan and 95 in ANWC. Due to geographical restrictions, most of the meteorological station data only covered up to 2000. Moreover, there were a few stations with data covered up to 2008 and one station with data only extended to 1995 . To ensure the representative and reliability of data, we produced a series of data that covered up to 2000 in this study. Some data which did not cover the period up to 2000 were extended by a linear regression method using data from surrounding regions.

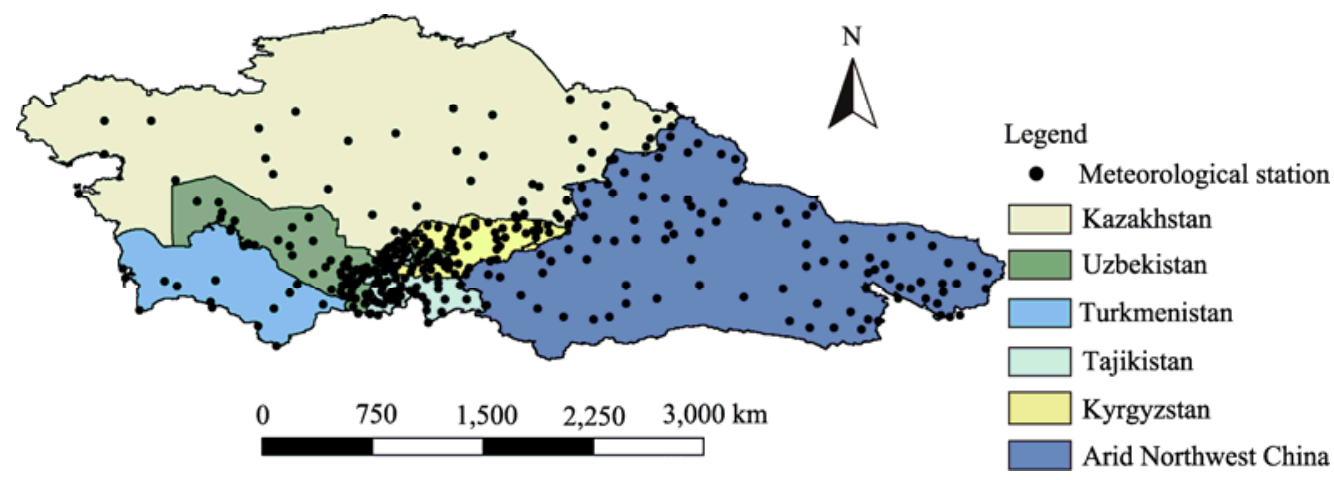

Fig. 1 Sketch map of the study area and distribution of meteorological stations 


\subsection{Study methods}

\subsubsection{Run theory}

Run theory refers to the continuous appearance of the same events. Annual precipitation $\left(P_{i}, i=1,2, \ldots, n\right)$ can be considered to be a discrete sequence. The mean annual precipitation $\left(P_{0}\right)$ was regarded as the threshold value. If $P_{i}>P_{0}$, there is a positive variation, i.e. a period with abundant precipitation; if $P_{i} \leq P_{0}$, there is a negative variation, i.e. a period with little precipitation. When $P_{i}>P_{0}$ or $P_{i} \leq P_{0}$ occurs more than twice in succession, the period is referred to as continuous wet or dry years, with the former being referred to as positive runs and the latter as negative runs, thereby analyzing the variations in precipitation (Kan, 1986). The probability of a run can be calculated based on the following formulae.

$$
\begin{gathered}
\mathrm{P}=\rho^{(\mathrm{K}-1)} \times(1-\rho), \\
\rho=\left(S-S_{1}\right) / S .
\end{gathered}
$$

Where, $\mathrm{P}$ is the probability of $\mathrm{K}$ wet or dry years in a row; $\mathrm{K}$ is the number of continuous wet or dry years; $\rho$ is a parameter of model distribution; $S$ is the occurrence of wet or dry years in the statistics; and $S_{1}$ is the number of times when continuous wet or dry years occurrence.

\subsubsection{PCI and standardization}

PCI shows the differentiation of precipitation and can be calculated by Eq. 3 (De et al., 2000).

$$
\mathrm{PCI}=100 \frac{\sum_{i=1}^{12} P_{i}^{2}}{\left(\sum_{i=1}^{12} p_{i}\right)^{2}} .
$$

Where $P_{i}$ is the monthly precipitation at each site. When $\mathrm{PCI}<10$, the precipitation is distributed evenly within the year; when $11 \leq \mathrm{PCI} \leq 20$, the precipitation displays seasonal changes; and when PCI $>20$, the precipitation displays large changes.

We calculated the coefficient of variation of precipitation (CVP) and the coefficient of variation of precipitation concentration index (CVPCI) according to the annual precipitation at each station and the value of PCI, to reflect the changes in the temporal sequence of precipitation. The larger the coefficient of variation is, the more the sequence changes. Furthermore, we also calculated the standard annual precipitation (SAP) and the standard precipitation concentration index (SPCI) based on the improved data standardization formulae (Eq. 4 and Eq. 5, respectively) to reveal the characteristics of annual precipitation variations.

$$
\begin{gathered}
S A P_{z i}=\left(P_{z i}-\overline{P_{z}}\right) / \overline{P_{z}}, \\
S P C I_{z i}=\left(P C I_{z i}-\overline{P C I_{z}}\right) / \overline{P C I_{z}} .
\end{gathered}
$$

Where, $P_{z i}$ is the annual precipitation of the $i$-th year at station $Z ; \bar{P}_{z}$ is the average annual precipitation at station $\mathrm{Z} ; P C I_{z i}$ is the PCI of the $i$-th year at station $Z$; and $\overline{P C I_{z}}$ is the average PCI at station $\mathrm{Z}$.

\subsubsection{Mann-Kendall rank correlation method}

The Mann-Kendall rank correlation method (Yue et al., 2002) was used in this study to explain the sequences in the trends and variability of precipitation. The fundamental principle of this method is that in the temporal sequence $P_{i}(i=1,2, \ldots, n)$ or any of its allelomorphs $\left(P_{i}, P_{j}, j>i\right)$, if $P_{i}>P_{j}$, the sequence is ascending, and vice versa. We also defined another parameter $(m)$ for evaluating precipitation tendency if the sequence is not clearly ascending or descending.

$$
\begin{gathered}
m=\frac{\tau}{\operatorname{var}(\tau)^{0.5},} \\
\tau=\frac{4 f}{[n(n-1)]-1}, \\
\operatorname{var}(\tau)=\frac{2(2 n+5)}{[9 n(n-1)]} .
\end{gathered}
$$

Where, $n$ is the length of precipitation data series, and $f$ is the $\log$ of an ascending allelomorph. If $m>0$, the sequence will ascend, but otherwise the sequence will descend. The larger the absolute value of $m$ is, the more significant the sequence changes become. The critical testing value of $m$ was \pm 1.96 when $P=0.05$.

\section{Results}

\subsection{Characteristics of precipitation in wet and dry years in the ALCA}

\subsubsection{Variability of precipitation}

We analyzed the characteristics of precipitation in wet and dry years from 1950 to 2000 in this study in terms of run theory (Cai, 2003) based on the annual precipitation series in the ALCA (Table 1). The longest wet period was smaller than the longest dry period in each 
area of the ALCA, with drought developing into the main feature of the climate in this region. The average dry period in the entire area was 5 years, with an average annual water deficit of $34.6 \mathrm{~mm}$ (accounting for $11.2 \%$ of the average annual precipitation over the period). In terms of each geographical area, the longest dry period in Kazakhstan was up to 10 years, with an average annual water deficit of $47.4 \mathrm{~mm}$ (accounting for $13.8 \%$ of the average annual precipitation over the period). The longest dry period in Tajikistan (3 years) was the shortest, with an average annual water deficit of $72.4 \mathrm{~mm}$ (accounting for $15.8 \%$ of the average annual precipitation over the period). In the other areas, the longest dry period lasted for 5 to 7 years, and the average annual water deficit accounted for $9.17 \%-17.92 \%$ of the average annual precipitation over the period. With regard to the average annual water deficit, Turkmenistan experienced the most serious water shortage (17.92\%) and then followed by
Tajikistan (15.80\%), while the ANWC had the least water shortage $(9.17 \%)$.

\subsubsection{Occurrence probability of wet and dry years}

Displacement theory was used to determine the occurrence probability of continuous wet or dry years at each site (Table 2). The occurrence probability of a single year with abundant precipitation was higher than that of a single year with less precipitation. The model parameter $\rho$ reflects the occurrence probability of continuous wet or dry years. If the parameter representing continuous dry years is larger than the one for continuous wet years, it is more likely that a series of continuous dry years will be experienced. The occurrence probability of a single year with abundant precipitation in the ALCA was $41.0 \%$, while it was $40.0 \%$ in a single year with less precipitation (Table 2). Turkmenistan was the country with the largest occurrence probability of a single year with abundant precipitation $(60.7 \%)$, and the occurrence probability of

Table 1 Characteristics of precipitation in wet and dry years in the ALCA

\begin{tabular}{|c|c|c|c|c|c|c|c|c|c|c|c|}
\hline \multirow{3}{*}{ Area } & \multirow{3}{*}{$\begin{array}{l}\text { Annual } \\
\text { precipitation } \\
(\mathrm{mm})\end{array}$} & \multicolumn{2}{|c|}{ Positive run-length } & \multicolumn{3}{|c|}{ Sum of positive runs } & \multicolumn{2}{|c|}{ Negative run-length } & \multicolumn{3}{|c|}{ Sum of negative runs } \\
\hline & & $\begin{array}{c}\text { Longest } \\
\text { wet period }\end{array}$ & Mean & Mean & MSD & $\begin{array}{c}\text { Abundant } \\
\text { precipitation }\end{array}$ & $\begin{array}{l}\text { Longest } \\
\text { dry period }\end{array}$ & Mean & Mean & MSD & $\begin{array}{c}\text { Water } \\
\text { shortage }\end{array}$ \\
\hline & & \multicolumn{2}{|c|}{ (a) } & \multicolumn{3}{|c|}{$(\mathrm{mm})$} & \multicolumn{2}{|c|}{ (a) } & \multicolumn{3}{|c|}{$(\mathrm{mm})$} \\
\hline Kazakhstan & 342.5 & 6 & 2.1 & 106.6 & 103.23 & $1,278.7$ & 10 & 2.3 & 106.6 & 226.69 & 47.4 \\
\hline Kyrgyzstan & 442.1 & 5 & 2.0 & 108.3 & 111.95 & $1,299.9$ & 5 & 2.3 & 108.3 & 93.33 & 48.1 \\
\hline Tajikistan & 458.1 & 4 & 2.4 & 138.1 & 129.53 & $1,519.5$ & 3 & 1.8 & 126.6 & 192.98 & 72.4 \\
\hline Turkmenistan & 179.7 & 4 & 1.8 & 64.4 & 44.26 & 837.0 & 7 & 2.0 & 64.4 & 70.68 & 32.2 \\
\hline Uzbekistan & 368.2 & 4 & 2.0 & 119.4 & 95.74 & $1,313.8$ & 5 & 2.7 & 119.4 & 81.97 & 43.8 \\
\hline ANWC & 137.4 & 4 & 1.7 & 30.6 & 20.50 & 428.8 & 7 & 2.4 & 30.6 & 28.56 & 12.6 \\
\hline ALCA & 308.5 & 5 & 2.7 & 86.4 & 64.13 & 864.3 & 5 & 2.5 & 86.4 & 71.79 & 34.6 \\
\hline
\end{tabular}

Note: ANWC, arid Northwest China; ALCA, arid lands of Central Asia; MSD, mean square deviation.

Table 2 The occurrence probability of wet and dry years in the ALCA

\begin{tabular}{|c|c|c|c|c|c|c|c|c|c|c|c|c|c|c|}
\hline \multirow{3}{*}{ Area } & \multicolumn{7}{|c|}{ Wet year } & \multicolumn{7}{|c|}{ Dry year } \\
\hline & \multirow{2}{*}{$\rho$} & \multirow{2}{*}{$\begin{array}{c}\text { Mean } \\
\text { continuous } \\
\text { years (a) }\end{array}$} & $\begin{array}{c}1 \\
\text { year }\end{array}$ & $\begin{array}{c}2 \\
\text { years }\end{array}$ & $\begin{array}{c}3 \\
\text { years }\end{array}$ & $\begin{array}{c}4 \\
\text { years }\end{array}$ & $\begin{array}{c}>5 \\
\text { years }\end{array}$ & \multirow{2}{*}{$\rho$} & \multirow{2}{*}{$\begin{array}{c}\text { Mean } \\
\text { continuous } \\
\text { years }(a)\end{array}$} & $\begin{array}{c}1 \\
\text { year }\end{array}$ & $\begin{array}{c}2 \\
\text { years }\end{array}$ & $\begin{array}{c}3 \\
\text { years }\end{array}$ & $\begin{array}{c}4 \\
\text { years }\end{array}$ & $\begin{array}{c}5 \\
\text { years }\end{array}$ \\
\hline & & & & & $(\%)$ & & & & & \multicolumn{5}{|c|}{$(\%)$} \\
\hline Kazakhstan & 0.52 & 2.1 & 48.5 & 25.0 & 12.9 & 6.7 & 3.5 & 0.52 & 2.1 & 48.4 & 25.0 & 12.9 & 6.7 & 3.4 \\
\hline Kyrgyzstan & 0.48 & 1.9 & 52.0 & 23.0 & 12.0 & 5.8 & 2.8 & 0.60 & 2.5 & 40.0 & 24.0 & 14.4 & 8.6 & 5.2 \\
\hline Tajikistan & 0.67 & 3.0 & 33.3 & 22.2 & 14.8 & 7.3 & 6.0 & 0.56 & 2.3 & 44.4 & 24.7 & 13.7 & 7.6 & 6.2 \\
\hline Turkmenistan & 0.39 & 1.6 & 60.7 & 23.9 & 9.4 & 3.7 & 1.4 & 0.47 & 1.9 & 53.1 & 24.9 & 11.7 & 5.5 & 2.6 \\
\hline Uzbekistan & 0.66 & 2.9 & 36.5 & 22.6 & 14.8 & 9.7 & 6.4 & 0.65 & 2.8 & 35.5 & 22.9 & 14.8 & 9.5 & 6.7 \\
\hline ANWC & 0.45 & 1.8 & 54.2 & 24.2 & 11.4 & 5.2 & 2.4 & 0.59 & 2.4 & 41.2 & 24.2 & 14.2 & 8.4 & 4.9 \\
\hline ALCA & 0.63 & 2.7 & 41.0 & 23.3 & 14.1 & 9.2 & 5.8 & 0.60 & 2.5 & 40.0 & 24.0 & 14.4 & 9.6 & 6.2 \\
\hline
\end{tabular}


a single year with abundant precipitation in ANWC was $54.2 \%$. In Turkmenistan, the occurrence probability of a single year with less precipitation was $53.1 \%$, while the occurrence probability of 4 and 5 consecutive dry years was $5.5 \%$ and $6.7 \%$, respectively, which suggested that Turkmenistan has experienced frequent drastic climate changes. Conversely, Uzbekistan was most likely to experience a continuous dry climate for more than 3 years.

2.1.3 Variability of the intensity of continuous drought

We calculated the Hurst coefficient $(\mathrm{H})$ in each area and for each meteorological station based on the R/S method (Feng et al., 2008), and divided the intensity of continuous drought into weak $(0.55<\mathrm{H} \leq 0.65)$, strong $(0.65<\mathrm{H} \leq 0.75)$ and pretty strong $(0.75<\mathrm{H} \leq 0.80)$ categories according to the study of Qing and Liu (2003). The distribution of Hurst coefficient in the ALCA is shown in Fig. 2. It can be seen from Table 3 that the Hurst coefficient in the study area was between 0.58 and 0.72 . The intensity of continuous drought in ANWC, Kyrgyzstan and Uzbekistan was strong, while it was weak in Kazakhstan, Turkmenistan and Tajikistan. The precipitation sequence in the study area has been determined over a long period, and the general climate change in the future is expected to be consistent with the trends and variability in the past. According to Fig. 2, the values of Hurst coefficient in ANWC and Kyrgyzstan were higher, while they were lower in Kazakhstan and Tajikistan.

\subsection{Changes in precipitation at multiple-time scales in the ALCA}

2.2.1 Characteristics of inter-annual and annual changes of precipitation

Contour maps of the parameters related to the temporal and spatial changes of precipitation in the ALCA were produced (Fig. 3). These parameters reflected the annual and inter-annual changes of precipitation. The average annual precipitation from 1950 to 2000 in the ALCA was $308.5 \mathrm{~mm}$, and the average annual precipitation in central Kyrgyzstan and Tajikistan was relatively high with the values between 400 and $700 \mathrm{~mm}$. The average annual precipitation in Uzbekistan, Turkmenistan and ANWC was low. Especially, the average annual precipitation in Turpan of China was only $36.1 \mathrm{~mm}$ (Fig. 3a). High values of CVP indicate very large inter-annual variations of precipitation. As shown in Fig. $3 \mathrm{~b}$, the values of CVP were quite small in Kyrgyzstan and Tajikistan. The inter-annual changes of precipitation were greater in Uzbekistan and Turkmenistan

Table 3 Hurst coefficient $(\mathrm{H})$ and intensity of continuous drought in the ALCA

\begin{tabular}{ccc}
\hline Area & $\mathrm{H}$ & Intensity level \\
\hline Kazakhstan & 0.64 & Weak \\
Turkmenistan & 0.62 & Weak \\
Kyrgyzstan & 0.69 & Strong \\
Uzbekistan & 0.66 & Strong \\
Tajikistan & 0.58 & Weak \\
ANWC & 0.72 & Strong \\
ALCA & 0.72 & Strong \\
\hline
\end{tabular}

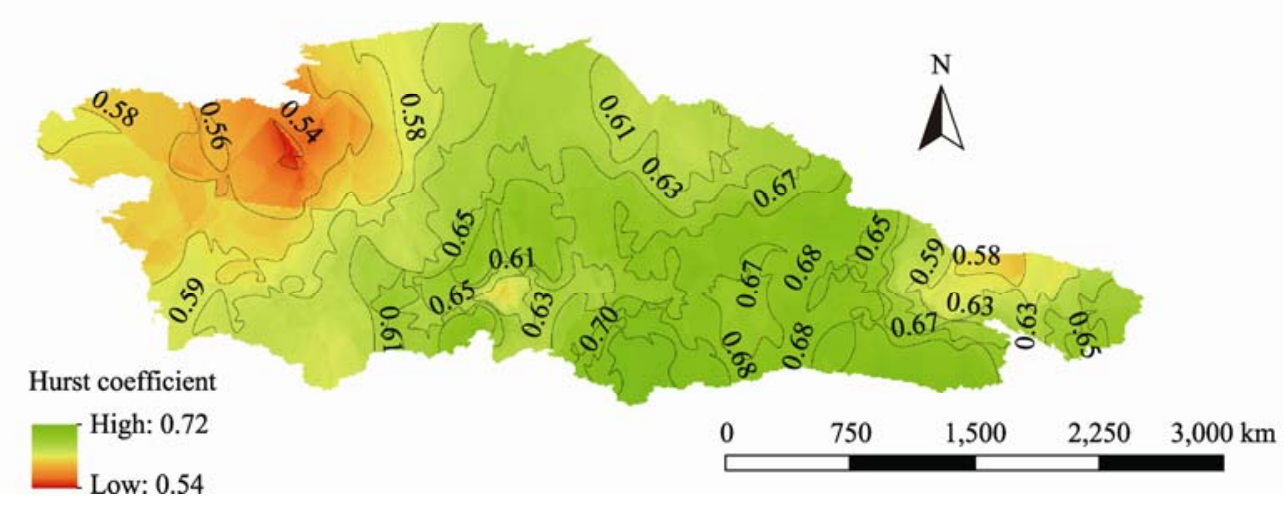

Fig. 2 Contour map of the Hurst coefficient in the ALCA (arid lands of Central Asia) 
(a) AP

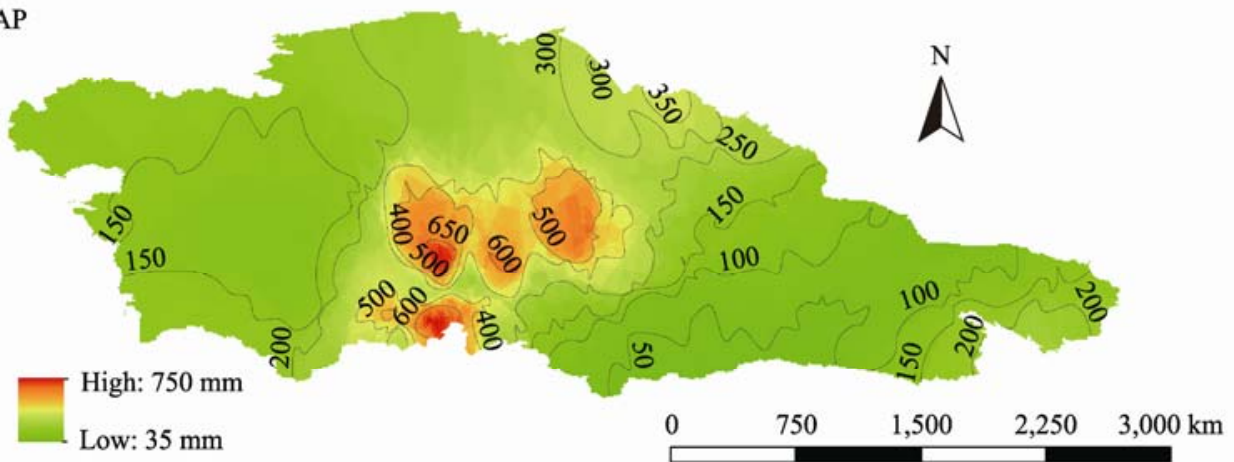

(b) CVP

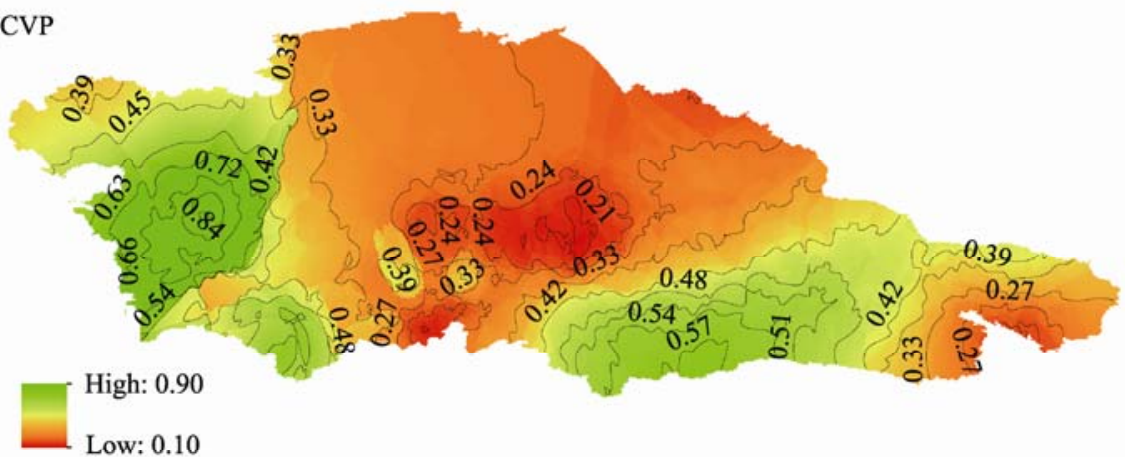

(c) PCI

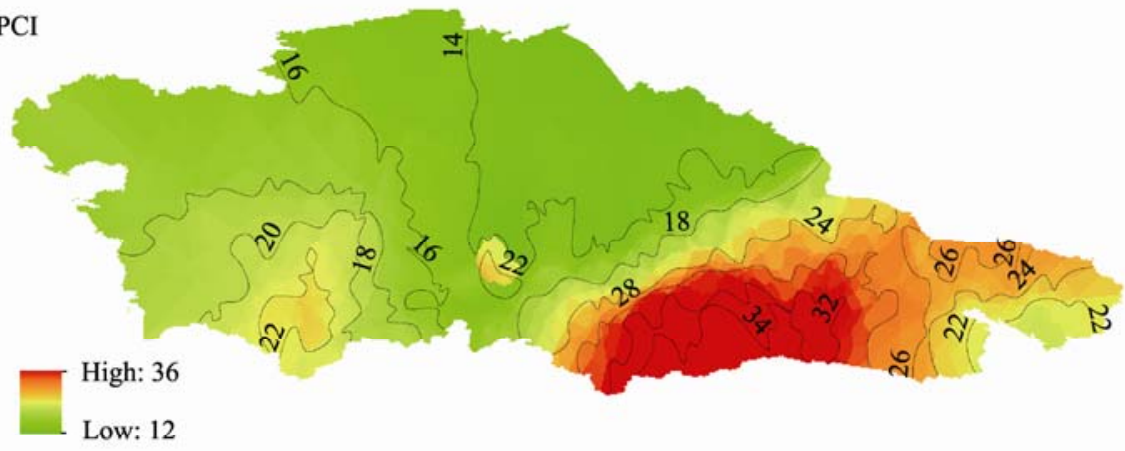

(d) CVPCI

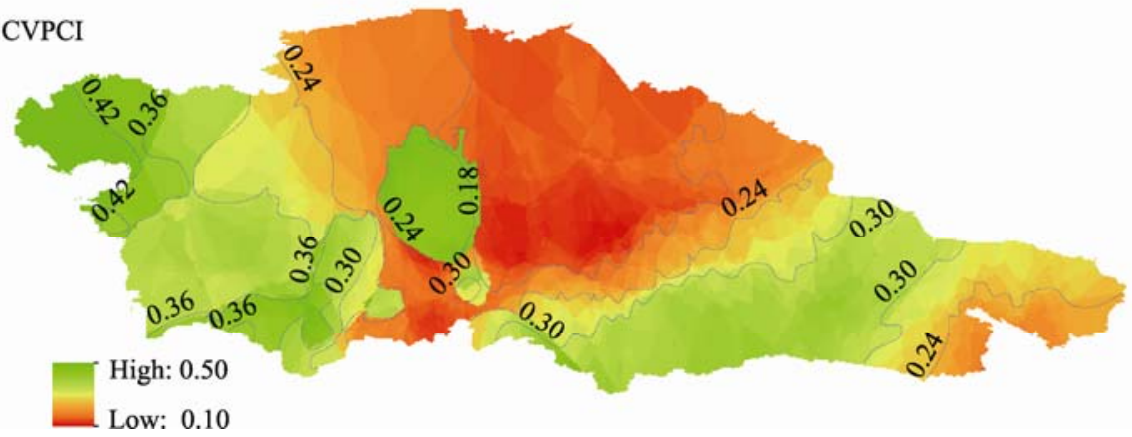

Fig. 3 Contour maps of precipitation parameters in the ALCA. (a) annual precipitation (AP); (b) coefficient of variation of precipitation (CVP); (c) precipitation concentration index (PCl); (d) coefficient of variation of precipitation concentration index (CVPCI).

$(\mathrm{CVP}=0.48-0.84)$. The average value of CVP in ANWC was larger than that in other areas. PCI reflects the distribution of annual precipitation. It ranged between 12 and 36 in the ALCA, indicating significant seasonal changes in precipitation (Fig. 3c). The values of PCI in ANWC were between 24 and 34, 
reflecting significant monthly changes of annual precipitation. CVPCI reflects the inter-annual changes of the distribution of precipitation. The inter-annual distribution of precipitation in the middle part of the ALCA was relatively stable with the values of CVPCI between 0.18 and 0.24 , while it fluctuated substantially in the western part of the ALCA (Fig. 3d).

2.2.2 Characteristics of decadal and seasonal changes of precipitation

The average precipitation, accumulated precipitation anomaly and percentage of years with a positive precipitation anomaly in each decade from the 1950s to 1990s were calculated for the study area (Table 4). The hydrography of annual precipitation in the ALCA was also determined to analyze the seasonal changes of precipitation in each decade (Fig. 4). From the 1950s to the early 1960 s, the climate was wet with accumulated precipitation anomaly reaching $286.54 \mathrm{~mm}$ (Table 4). The 1970s was a dry period, with accumulated precipitation anomaly of only $96.51 \mathrm{~mm}$. The period from the 1980s to the middle 1990s was also dry. Spring is a rainy season in the ALCA, with precipitation accounting for $37.7 \%$ of the average annual precipitation from 1950 to 2000 . Spring precipitation was lowest in the $1990 \mathrm{~s}$ ( $36.1 \%$ of the average annual precipitation), and highest in the $1960 \mathrm{~s}$ ( $41.4 \%$ of the average annual total). Precipitation in summer accounted for $18.8 \%$ of the average annual precipitation during
1950-2000, with the 1950s being the highest (19.7\%) and the 1970s being the lowest (15.5\%). In the 1990s, the accumulated precipitation anomaly in summer was $17.71 \mathrm{~mm}$. Precipitation in autumn accounted for $18.1 \%$ of the average annual precipitation. Winter is also a wet season, with precipitation accounting for $25.5 \%$ of the average annual precipitation from 1950 to 2000 . Winter precipitation was lowest in the $1960 \mathrm{~s}$ (22.3\%) and highest in the 1970s (27.4\%).

\subsection{Trends and variability of precipitation in the ALCA}

2.3.1 Trends and variability of annual precipitation and its anomaly

In this study, the Mann-Kendall rank correlation method was used to analyze the annual precipitation in each meteorological station in the ALCA. The changes of annual precipitation in the areas with different degrees of aridity are shown in Table 5, and the trends and variability of annual precipitation in the ALCA are shown in Fig. 5. Among the 344 typical meteorological stations, the probability of an increase in annual precipitation was $75.6 \%$, with this increase being significant $(P=0.05)$ at $34.0 \%$ of all the stations. However, the probability of a decrease in annual precipitation was $24.4 \%$, with this decrease being significant $(P=0.05)$ at $4.4 \%$ of all the stations. SAP tended to increase at $61.0 \%$ of all the stations, with

Table 4 Decadal and seasonal changes of precipitation in the ALCA from 1950 to 2000

\begin{tabular}{|c|c|c|c|c|c|c|c|}
\hline Duration & Item & $1950 \mathrm{~s}$ & $1960 s$ & $1970 \mathrm{~s}$ & $1980 \mathrm{~s}$ & $1990 \mathrm{~s}$ & $1950-2000$ \\
\hline \multirow[t]{3}{*}{ Whole year } & Average precipitation (mm) & 328.11 & 338.27 & 309.21 & 327.06 & 302.71 & 313.44 \\
\hline & Accumulated precipitation anomaly (mm) & 92.46 & 194.08 & -96.51 & 81.99 & -157.34 & 19.80 \\
\hline & Precipitation of years with a positive anomaly $(\%)$ & 53.33 & 51.67 & 43.33 & 45.00 & 43.75 & 44.93 \\
\hline \multirow[t]{3}{*}{ Spring } & Average precipitation (mm) & 128.32 & 139.97 & 122.42 & 124.48 & 109.42 & 118.07 \\
\hline & Accumulated precipitation anomaly (mm) & 64.37 & 180.88 & 5.38 & 25.91 & -113.90 & 17.87 \\
\hline & Precipitation of years with a positive anomaly $(\%)$ & 58.33 & 63.33 & 51.67 & 50.00 & 30.83 & 47.44 \\
\hline \multirow[t]{3}{*}{ Summer } & Average precipitation (mm) & 64.48 & 59.86 & 50.74 & 59.25 & 61.82 & 58.84 \\
\hline & Accumulated precipitation anomaly (mm) & 50.80 & 4.59 & -86.62 & -1.51 & 17.71 & -6.79 \\
\hline & Precipitation of years with a positive anomaly $(\%)$ & 51.67 & 38.33 & 25.00 & 41.67 & 56.67 & 44.47 \\
\hline \multirow[t]{3}{*}{ Autumn } & Average precipitation (mm) & 53.45 & 62.89 & 51.34 & 62.56 & 48.77 & 56.56 \\
\hline & Accumulated precipitation anomaly (mm) & -32.61 & 61.77 & -53.72 & 58.50 & -77.53 & -5.23 \\
\hline & Precipitation of years with a positive anomaly $(\%)$ & 31.67 & 60.00 & 38.33 & 60.00 & 30.83 & 46.39 \\
\hline \multirow[t]{3}{*}{ Winter } & Average precipitation (mm) & 81.85 & 75.54 & 84.68 & 80.77 & 82.70 & 79.96 \\
\hline & Accumulated precipitation anomaly (mm) & 9.94 & -53.13 & 38.26 & -0.88 & 16.41 & 13.93 \\
\hline & Precipitation of years with a positive anomaly (\%) & 50.00 & 38.33 & 53.33 & 50.00 & 49.58 & 46.04 \\
\hline
\end{tabular}



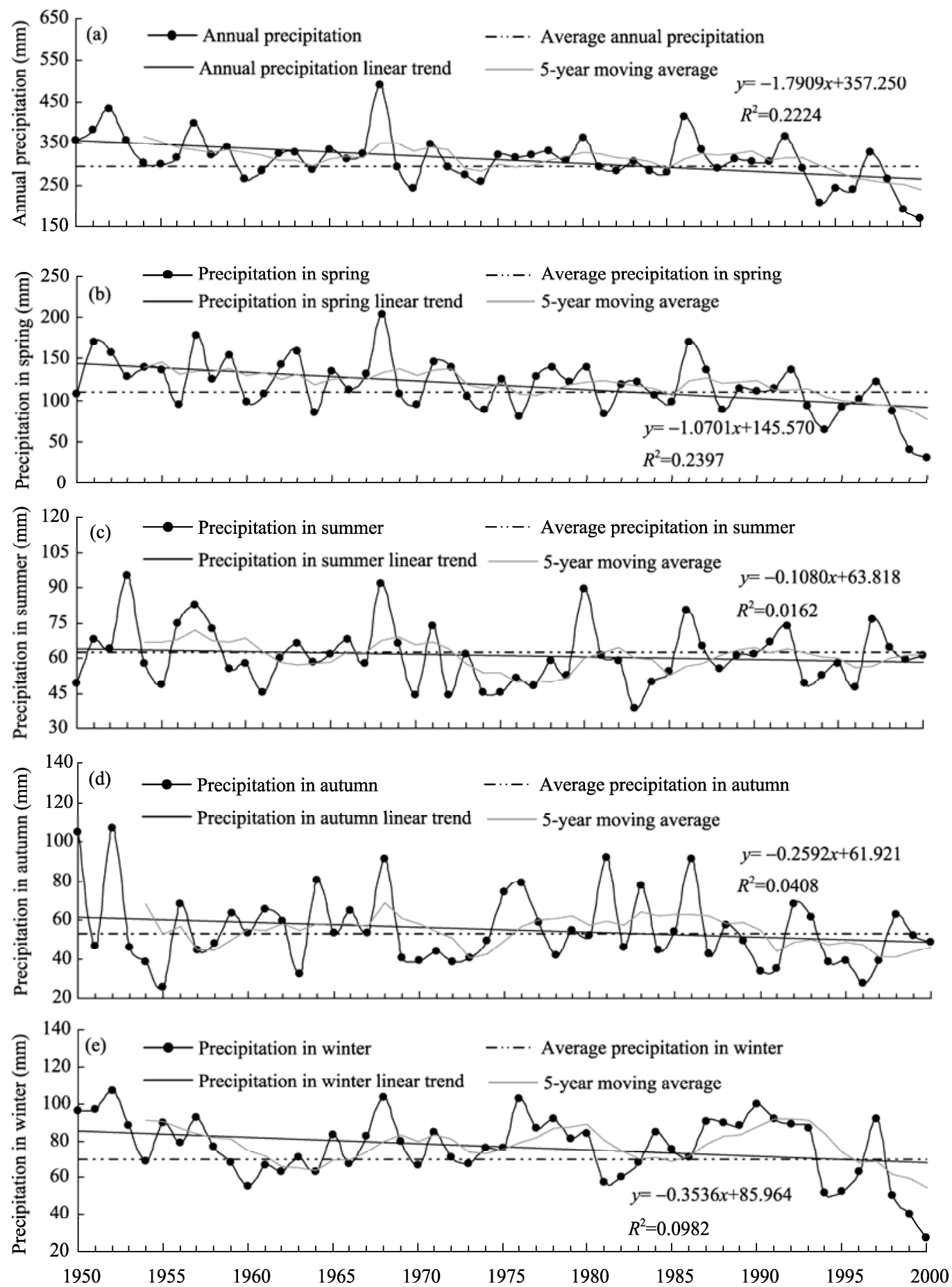

Fig. 4 Annual and seasonal changes of precipitation from 1950 to 2000 in the ALCA. (a) annual precipitation; (b) precipitation in spring; (c) precipitation in summer; (d) precipitation in autumn; (e) precipitation in winter.

this increase being significant $(P=0.05)$ at $17.4 \%$ of all the stations. The probability of an increase in annual precipitation in extremely arid, arid, semi-arid and semi-humid areas was $81.8 \%(36.4 \%$ of all the stations passing a significance test), $80.9 \%$ (37.3\% of all the stations passing a significance test), $68.6 \%$ (28.9\% of all the stations passing a significance test) and $76.9 \%$ (36.3\% of all the stations passing a significance test), respectively. The probability of a reduction in annual precipitation in semi-arid and semi-humid areas 
Table 5 Changes of annual precipitation (AP) and standard annual precipitation (SAP) in the areas with different degrees of aridity

\begin{tabular}{|c|c|c|c|c|c|c|c|}
\hline \multirow{2}{*}{ Area } & \multirow{2}{*}{$\begin{array}{c}\text { Number of } \\
\text { meteorological station }\end{array}$} & \multicolumn{3}{|c|}{ AP change $(\%)$} & \multicolumn{3}{|c|}{ SAP change $(\%)$} \\
\hline & & Increase & No change & Decrease & Increase & No change & Decrease \\
\hline Extremely arid area & 22 & $36.4(8)$ & $59.1(13)$ & $4.5(1)$ & $0.0(0)$ & $95.5(21)$ & $4.5(1)$ \\
\hline Arid area & 110 & $37.3(41)$ & $56.7(62)$ & $6.0(7)$ & $10.0(11)$ & $84.0(92)$ & $6.0(7)$ \\
\hline Semi-arid area & 121 & $28.9(35)$ & $66.9(81)$ & $4.2(5)$ & $23.1(28)$ & $70.2(85)$ & $7.0(8)$ \\
\hline Semi-humid area & 91 & $36.3(33)$ & $61.5(56)$ & $2.2(2)$ & $23.1(21)$ & $75.8(69)$ & $1.1(1)$ \\
\hline ALCA & 344 & $34.0(117)$ & $61.6(212)$ & $4.4(15)$ & $17.4(60)$ & $77.6(267)$ & $5.0(0)$ \\
\hline
\end{tabular}

Note: Extremely arid area, $\mathrm{AP} \leq 50 \mathrm{~mm}$; arid area, $50<\mathrm{AP} \leq 200 \mathrm{~mm}$; semi-arid area, $200<\mathrm{AP} \leq 400 \mathrm{~mm}$; semi-humid area, $400<\mathrm{AP} \leq 800 \mathrm{~mm}$. Number in the parentheses represents the number of meteorological stations.
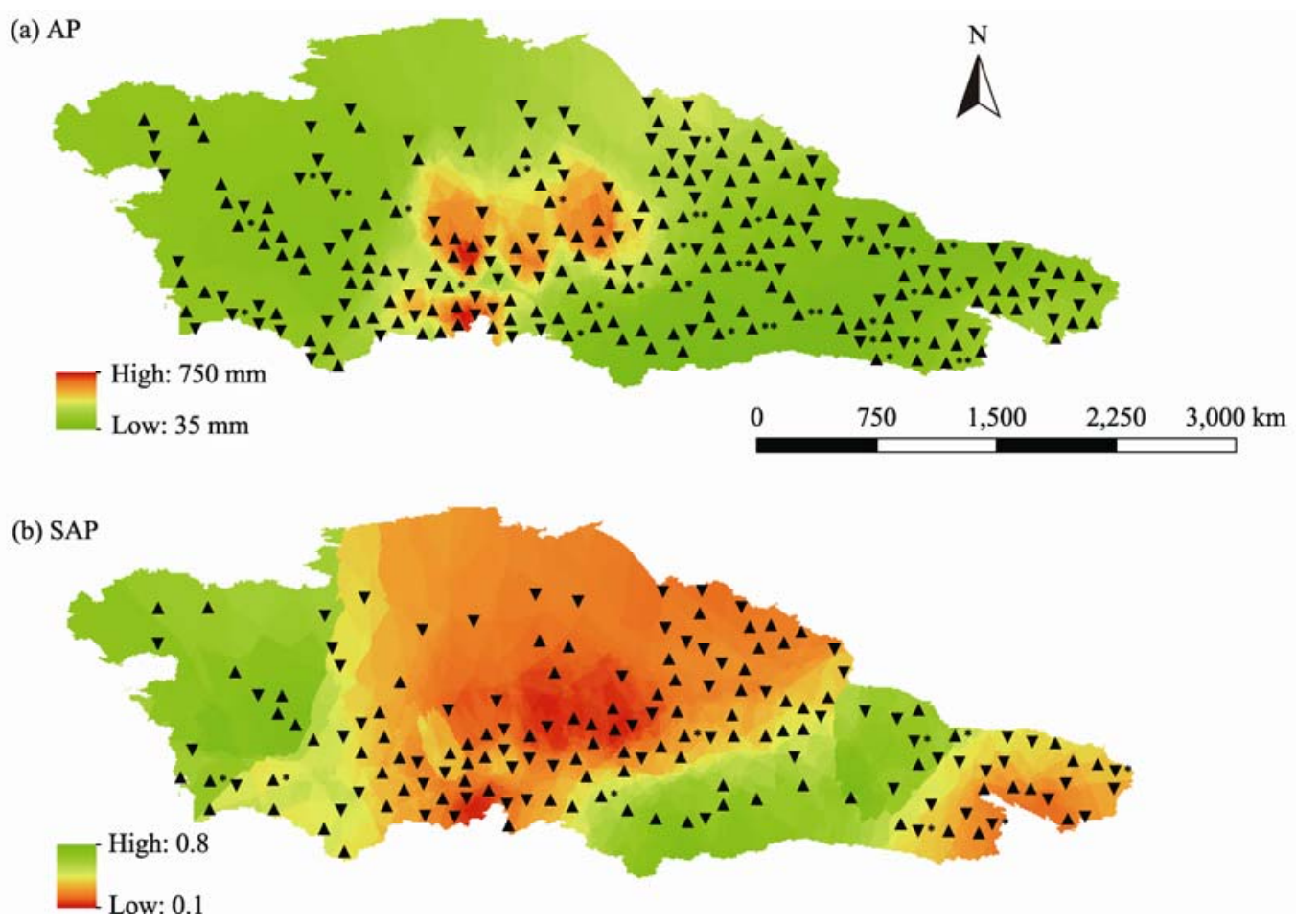

Fig. 5 Change trends of (a) annual precipitation (AP) and (b) standard annual precipitation (SAP) in the ALCA. $\mathbf{\Lambda}$, increasing tendency; $\boldsymbol{\nabla}$, decreasing tendency. ${ }^{*}$ and ${ }^{* *}$ mean significance at $P=0.05$ and $P=0.01$ levels, respectively.

was $31.4 \%$ (4.2\% of all the stations passing a significance test) and $23.1 \%$ (2.2\% of all the stations passing a significance test), respectively.

2.3.2 Trends and variability of PCI

We analyzed the values of PCI and SPCI at each meteorological station using the Mann-Kendall rank correlation method in this study (Table 6). The distribution of PCI and SPCI in the ALCA is shown in Fig. 6. Among the 344 meteorological stations, the probability of an increase in PCI was $47.1 \%$, with this increase being significant $(P=0.05)$ at $17.7 \%$ of all the stations. The probability of a decrease in PCI was $52.9 \%$, with this decrease being significant $(P=0.05)$ at $8.2 \%$ of all the stations. The probability of an increase in SPCI in extremely arid, arid, semi-arid and semi-humid areas was $45.5 \%$ (4.5\% of all the stations passing a significance test), $40.0 \%(9.1 \%$ of all the stations passing a significance test), $53.7 \%$ (21.5\% of all the stations passing a significance test) and $47.3 \%$ (19.8\% of all the stations passing a significance test), respectively. The probability of a decrease in SPCI in semi-arid area was as high as $72.7 \%$ (13.7\% of all the stations passing a significance test), which suggested that inter-annual variation of precipitation in semi-arid area will increase. 
Table 6 Change trends of precipitation concentration index $(\mathrm{PCI})$ and standard annual precipitation concentration index (SPCI) in the ALCA

\begin{tabular}{|c|c|c|c|c|c|c|c|}
\hline \multirow{2}{*}{ Area } & \multirow{2}{*}{$\begin{array}{l}\text { Number of } \\
\text { meteorological station }\end{array}$} & \multicolumn{3}{|c|}{ PCI change $(\%)$} & \multicolumn{3}{|c|}{ SPCI change $(\%)$} \\
\hline & & Increase & No change & Decrease & Increase & No change & Decrease \\
\hline Extremely arid area & 22 & $9.1(2)$ & $72.7(16)$ & $18.2(4)$ & $4.5(1)$ & $81.8(18)$ & $13.7(3)$ \\
\hline Arid area & 110 & $13.6(15)$ & $73.6(81)$ & $12.8(14)$ & $9.1(10)$ & $86.7(95)$ & $4.2(5)$ \\
\hline Semi-arid area & 121 & $23.1(28)$ & $72.7(88)$ & $4.2(5)$ & $21.5(26)$ & $76.8(93)$ & $1.7(2)$ \\
\hline Semi-humid area & 91 & $17.6(16)$ & $77.8(70)$ & $5.6(5)$ & $19.8(18)$ & $76.9(70)$ & $3.3(3)$ \\
\hline ALCA & 344 & $17.7(61)$ & $74.1(255)$ & $8.2(28)$ & $16.0(0)$ & $80.2(276)$ & $3.8(13)$ \\
\hline Area with $11 \leq \mathrm{PCI} \leq 20$ & 242 & $22.7(55)$ & $71.9(174)$ & $5.4(13)$ & $21.9(53)$ & $75.6(183)$ & $2.5(6)$ \\
\hline Area with $\mathrm{PCI}>20$ & 102 & $6.9(7)$ & $79.4(81)$ & $13.7(14)$ & $1.9(2)$ & $91.2(93)$ & $6.9(7)$ \\
\hline ALCA & 344 & $18.0(62)$ & $74.1(255)$ & $7.9(27)$ & $16.0(55)$ & $80.2(276)$ & $3.8(13)$ \\
\hline
\end{tabular}

Note: Number in the parentheses represents the number of meteorological stations.

(a) $\mathrm{PCI}$

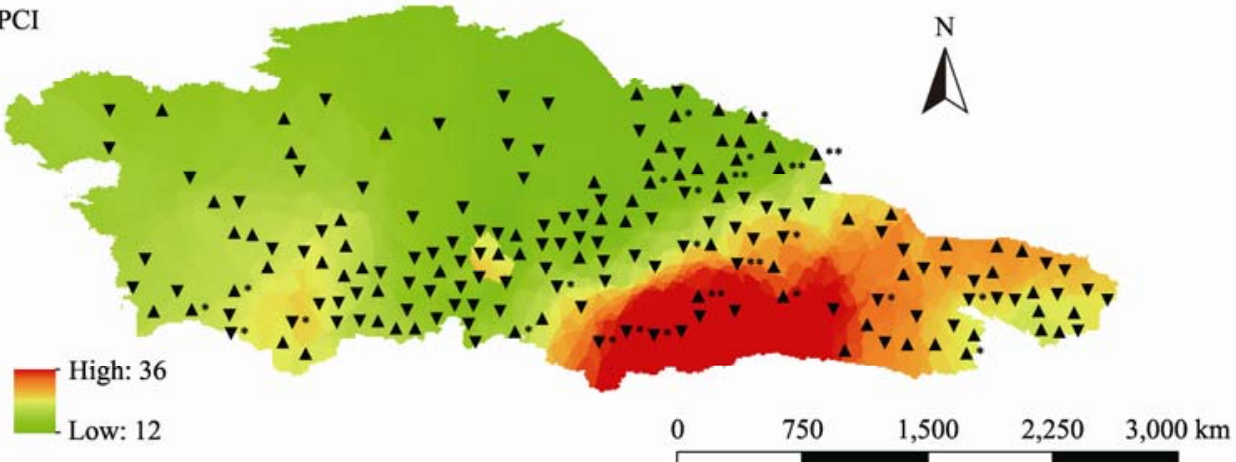

(b) SPCI

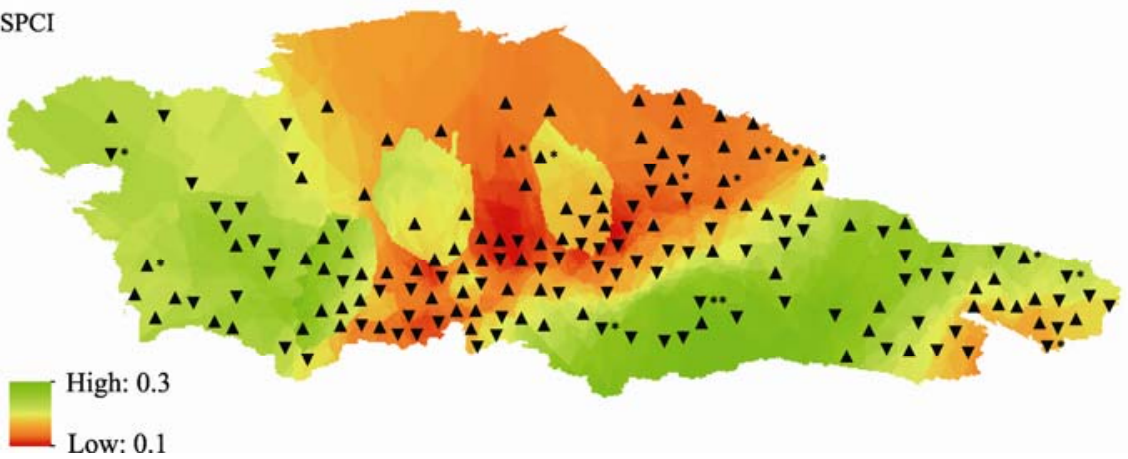

Fig. 6 Change trends in (a) precipitation concentration index $(\mathrm{PCl})$ and $(\mathrm{b})$ standard precipitation concentration index (SPCl) in the ALCA. $\boldsymbol{\Delta}$, increasing tendency; $\boldsymbol{\nabla}$, decreasing tendency. * and ${ }^{* *}$ mean significance at $P=0.05$ and $P=0.01$ levels, respectively.

\subsubsection{Variation gradient of annual precipitation}

The climate trend coefficient method (Ren et al., 2005) was used to analyze the change trends of annual precipitation and calculate the change rate of precipitation at each meteorological station (Table 7). The trends and variability of annual precipitation in the ALCA is shown in Fig. 7. The annual precipitation in the ALCA displayed an increasing trend, with the rate of $3.9 \mathrm{~mm} / 10 \mathrm{a}(P=0.01)$. The annual precipitation in
Kazakhstan, Kyrgyzstan and Tajikistan tended to increase $(P=0.01)$, with the rates of 2.6, 3.1 and 3.7 $\mathrm{mm} / 10 \mathrm{a}$, respectively. Moreover, the annual precipitation in ANWC also increased at the rate of $1.8 \mathrm{~mm} / 10 \mathrm{a}$ $(P=0.05)$. Both of the variations in annual precipitation and PCI were insignificant. The variations of SPCI in Turkmenistan, Uzbekistan and ANWC were significant $(P=0.05)$, and the monthly precipitations in Turkmenistan and Uzbekistan were discrete. 
Table 7 Change trends of annual precipitation (AP), standard annual precipitation (SAP), precipitation concentration index (PCI) and standard precipitation concentration index (SPCI) in the ALCA

\begin{tabular}{|c|c|c|c|c|c|c|c|c|}
\hline \multirow{2}{*}{$\begin{array}{l}\text { Precipitation } \\
\text { parameter }\end{array}$} & \multirow{2}{*}{$\begin{array}{l}\text { Calculation } \\
\text { parameter }\end{array}$} & \multicolumn{7}{|c|}{ Area } \\
\hline & & Kazakhstan & Kyrgyzstan & Tajikistan & Turkmenistan & Uzbekistan & ANWC & ALCA \\
\hline \multirow[t]{3}{*}{ AP } & Testing parameters & 3.934 & 4.313 & 6.384 & 0.067 & 1.461 & 1.223 & 2.897 \\
\hline & Change trend & $\boldsymbol{\Delta}^{* *}$ & $\boldsymbol{\Delta}^{* *}$ & $\boldsymbol{\Delta}^{* *}$ & $\Delta$ & $\Delta$ & $\mathbf{\Delta}^{*}$ & $\mathbf{\Delta}^{* *}$ \\
\hline & Change rate $(\mathrm{mm} / 10 \mathrm{a})$ & 2.6 & 3.1 & 3.7 & 0.2 & 4.2 & 1.8 & 3.9 \\
\hline \multirow[t]{3}{*}{ SAP } & Testing parameters & -0.187 & 0.606 & -0.474 & 0.426 & 0.411 & -0.101 & 0.114 \\
\hline & Change trend & $\nabla$ & $\Delta$ & $\nabla$ & $\Delta$ & $\Delta$ & $\nabla$ & $\Delta$ \\
\hline & Change rate $(\mathrm{mm} / 10 \mathrm{a})$ & -0.2 & 2.8 & -1.5 & 1.0 & 2.1 & -0.2 & 0.7 \\
\hline \multirow[t]{3}{*}{ PCI } & Testing parameters & -0.187 & 0.606 & -0.474 & 0.426 & 0.411 & -0.101 & 0.114 \\
\hline & Change trend & $\nabla$ & $\Delta$ & $\nabla$ & $\Delta$ & $\Delta$ & $\boldsymbol{\nabla}$ & $\Delta$ \\
\hline & Change rate $(\mathrm{mm} / 10 \mathrm{a})$ & -0.2 & 3.8 & -2.5 & 1.0 & 2.1 & -0.1 & 0.7 \\
\hline \multirow[t]{3}{*}{ SPCI } & Testing parameters & 0.941 & 1.350 & 0.763 & 1.933 & 1.685 & -1.789 & 0.808 \\
\hline & Change trend & $\Delta$ & $\boldsymbol{\Delta}$ & $\Delta$ & $\mathbf{\Delta}^{*}$ & $\mathbf{\Delta}^{*}$ & $\boldsymbol{\nabla}^{*}$ & $\Delta$ \\
\hline & Change rate $(\mathrm{mm} / 10 \mathrm{a})$ & 0.4 & 2.1 & 1.1 & 1.5 & 1.3 & -0.4 & 0.5 \\
\hline
\end{tabular}

Note: $\boldsymbol{\Lambda}$, increasing tendency; $\boldsymbol{\nabla}$, decreasing tendency. ${ }^{*}$ and ${ }^{* *}$ mean significance at $P=0.05$ and $P=0.01$ levels, respectively.

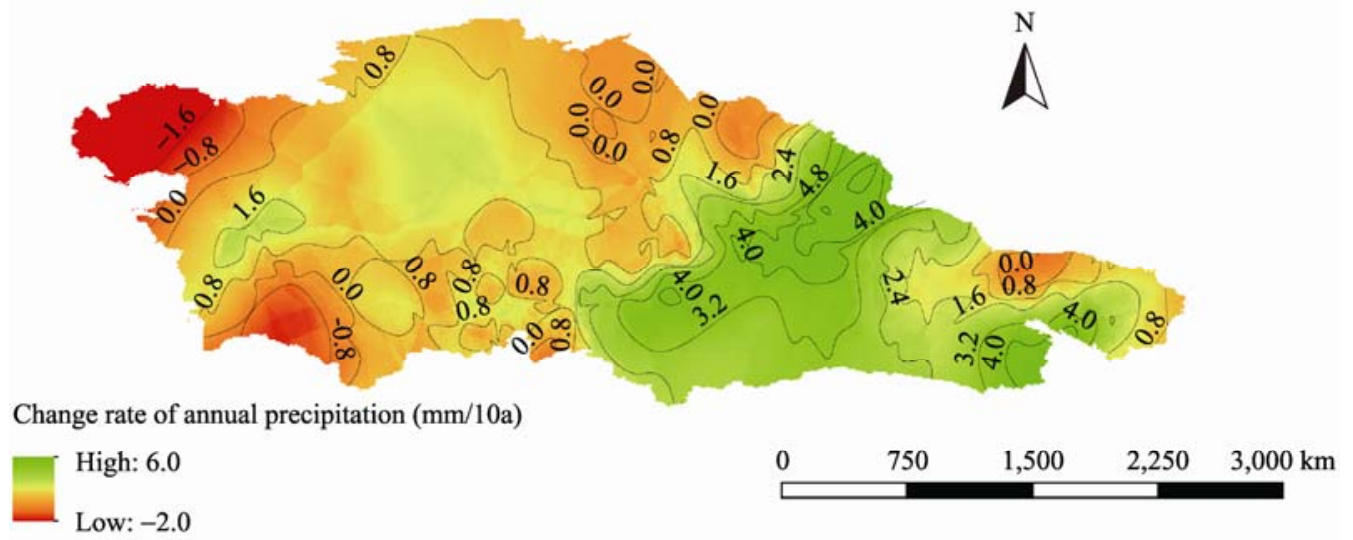

Fig. 7 Distribution of change rate of precipitation in the ALCA

\section{Discussion}

Our research indicated that annual precipitation in the ALCA has displayed an increasing trend, with the rate of $3.9 \mathrm{~mm} / 10 \mathrm{a}(P=0.01)$. We considered how this result conforms to the actual situation 10 years later. We loaded the monthly precipitation data of 95 meteorological stations in ANWC during 1950-2010 from http://cdc.cma.gov.cn and analyzed the changes of annual precipitation in this region. The average annual precipitation was $136.0 \mathrm{~mm}$ during $1950-2000$, but it increased to $148.2 \mathrm{~mm}$ for the period of 2001-2010. This confirmed that the annual precipitation in ANWC is actually increasing. In addition,
Huang et al. (2013) reported that the temperature has reduced dramatically in the upper troposphere over the summer in Northwest China since the 1970s, and increased significantly in the lower troposphere over the arid zone of Northwest China, which has accompanied precipitation increases in the region since the 1970s. Using a series of precipitation data from 1961 to 2010, Yao et al. (2013) determined an increasing trend in precipitation in Northwest China, with the annual and winter precipitation increasing significantly by 9.52 and $2.34 \mathrm{~mm} / 10 \mathrm{a}$, respectively. Since the $1960 \mathrm{~s}$, precipitation has also displayed a tendency of increase in the mountainous area of the Hexi inland river basin (Lan et al., 2012). Lioubimtseva and Henebry (2009) 
reported a slight decrease in average annual precipitation in the ALCA. Changes in the spatio-temporal distribution of precipitation in the ALCA have been projected, with less precipitation in the central and southern parts, particularly during the summer, and an increase in winter precipitation in the northern and eastern parts (IPCC, 2007; Lioubimtseva and Henebry, 2009). In addition, a general increase in the frequency of extreme events is very likely (IPCC, 2007). By analyzing the standardized precipitation index, Oliver et al. (2012) found that the extreme precipitation in western China and Central Asia were above and below the normal, respectively. In Uzbekistan and Turkmenistan, precipitation mainly occurs from autumn to spring next year, with the maxima in March and April, respectively. ALCA is characterized by an obvious inter-annual variability of precipitation, where both occasional drought events and wet growing seasons are common (Henkin et al., 2007; Wehrden et al., 2010). In the ALCA, the annual and seasonal precipitations have both increased during the past 80 years (Chen et al., 2011). The annual precipitation in the ALCA is increasing at a rate of $1.2 \mathrm{~mm} / 10 \mathrm{a}$, and the increasing trend is strongest in winter, with a rate of $0.7 \mathrm{~mm} / 10 \mathrm{a}$ (significant at the $95 \%$ confidence level), followed by autumn $(0.3 \mathrm{~mm} / 10 \mathrm{a})$, summer $(0.2$ $\mathrm{mm} / 10 \mathrm{a})$ and spring $(0.1 \mathrm{~mm} / 10 \mathrm{a}$; Chen et al., 2011).

In the ALCA, the strength of the westerlies and the associated changes of water vapor at the middle latitudes are likely the major factors that influence the precipitation variation. The scarce water resources, fragile ecosystems and strong human impacts on natural environment mean that this region is highly sensitive to changes in characteristics of precipitation caused by temperature anomalies such as global warming (Trenberth et al., 2003; Narisma et al., 2007). However, more detailed studies need to perform on how these factors respond to global warming and impact on the increasing precipitation as well as their regional differences and mechanisms.

\section{Conclusions}

In this study, we used run theory, extreme deviation theory and PCI method to analyze the characteristics of intra-annual, inter-annual, seasonal and in- ter-decadal precipitation, and used Mann-Kendall rank correlation and climatic trend coefficient methods to discuss the tendency and change rate of precipitation in the ALCA. We found that precipitation in the ALCA is very sensitive to global warming. Precipitation showed significant inter-annual variations in many parts of the ALCA, especially in ANWC (the values of PCI ranging from 24 to 34 ). In the past 50 years, precipitation in spring and winter occupied $37.7 \%$ and $24.4 \%$ of the average annual precipitation, respectively; however, in summer it just accounted for $17.9 \%$ of the average annual precipitation.

In the ALCA, the spatial distribution of precipitation and precipitation tendency in the future also showed different regional features. Precipitation is expected to increase in all parts of the ALCA except the western Kazakhstan, with rates of 2.6, 3.1, 3.7 and $1.8 \mathrm{~mm} / 10 \mathrm{a}$ in major Kazakhstan, Kyrgyzstan, Tajikistan and ANWC, respectively. Precipitation in western Kazakhstan displayed a decreasing trend, with the rate of $1.96 \mathrm{~mm} / 10 \mathrm{a}$.

The landscape of ALCA is diversity, containing ice, forest, grassland, oasis and deserts along with the vertical gradient of altitude. Precipitation is abundant in the mountainous areas in the ALCA, while scarce in the basin areas, and therefore it is of great significance in the sustainable development of ecological systems, local economy and society. Further studies are required to determine the main causes for the changes in local precipitation under the combined influence of global climate change and human activities. The influences of precipitation changes on ecological systems and development of local water and soil resources also need to be studied.

\section{Acknowledgements}

This research was financially supported by International Science \& Technology Cooperation Program of China (2010DFA92720), the Knowledge Innovation Project of the Chinese Academy of Sciences (KZCX2-YW-T09) and the Post-doctoral Fund Program of China (2013M542416). The authors are indebted to two anonymous reviewers and the associated editor for their helpful and constructive comments and suggestions for improving the manuscript. The authors also thank LIU Hao and ZHOU Qian for their help with the field work. 


\section{References}

Aizen E M, Aizen V B, Melack J M, et al. 2001. Precipitation and atmospheric circulation patterns at mid-latitudes of Asia. International Journal of Climatology, 21: 535-556.

Cai M K. 2003. Comparative study on hydrologic-meteorologicaldrought characteristics of Guanzhong areas. Journal of Irrigation and Drainage, 22(6): 33-37. (in Chinese)

Chen F H, Chen J H, Huang W. 2009. Discussion on "westerly mode" of climate change in the middle laltitude during the ice age. Earth Science Frontiers, 16(6): 23-32.

Chen F H, Chen J H, Holmes J, et al. 2010. Moisture changes over the last millennium in arid central Asia: a review, synthesis and comparison with monsoon region. Quaternary Science Reviews, 29: 1055-1068.

Chen F H, Huang W, Jin L Y, et al. 2011. Spatiotemporal precipitation variations in the arid Central Asia in the context of global warming. Science China Earth Sciences, 54(12): 1812-1821.

De L M, Raventos J, Gonza J C, et al. 2000. Spatial analysis of rainfall trends in the region of Valencia (East Spain). International Journal of Climatology, 20: 1451-1469.

Feng X L, Feng Z L, Luo L C, et al. 2008. Fractal analysis of climate change and Hurst index experiment in Tibetan Plateau in future. Arid Land Geography, 31(2): 175-181. (in Chinese)

Hedi O, Katerina N, Anna P, et al. 2011. Variability in precipitation, temperature and river runoff in Central Asia during the past $2000 \mathrm{yrs}$. Global and Planetary Change, 76: 95-104.

Henkin Z, Hadar L, Noy M I. 2007. Human-scale structural heterogeneity induced by grazing in a Mediterranean woodland landscape. Landscape Ecology, 22: 577-587.

Huang R H, Zhou D G, Chen W, et al. 2013. Recent progress in studies of air-land interaction over the ANWC and its impact on climate. Chinese Journal of Atmospheric Sciences, 37(2): 189-210. (in Chinese)

IPCC. 2007. Summary for Policymakers of Climate Change 2007: The Physical Science Basis. Contribution of Working Group I to the Fourth Assessment Report of the Intergovernmental Panel on Climate Change. Cambridge: Cambridge University Press, 4-6.

Kan G S. 1986. Preliminary discussion of agricultural drought based on displacement theory. Journal of China Hydrology, 2: 12-18. (in Chinese)

Lan Y C, Xiao H L, Hu X L, et al. 2012. Study of temperature and precipitation change in upstream mountain area of the Hexi inland river basin since 1960s. Sciences in Cold and Arid Regions, 4(6): 522-535.

Li F P, Zhang Y Q, Xu Z X. 2013. The impact of climate change on runoff in the southeastern Tibetan Plateau. Journal of Hydrology, 505: 188-201.

Lioubimtseva E, Colea R, Adams J M, et al. 2005. Impacts of climate and land-cover changes in arid lands of Central Asia. Journal of Arid Environments, 62: 285-308.
Lioubimtseva E, Henebry G M. 2009. Climate and environmental change in arid Central Asia: Impacts, vulnerability and adaptations. Journal of Arid Environments. 73: 963-977.

Narisma G T, Foley J A, Licker R, et al. 2007. Abrupt changes in rainfall during the twentieth century. Geophysical Research Letters, 34(6), L06710, doi: 10.1029/2006GL028628.

Oliver B, Klaus F, Zhu X H. 2012. Precipitation climate of Central Asia and the large-scale atmospheric circulation. Theoretical and Applied Climatology, 108(3-4): 345-354.

Qing Y C, Liu K. 2003. Advancement of applied studies of fractal theory in geography. Progress in Geography, 22(4): 426-436. (in Chinese)

Ren J M, You L, Gao J F, et al. 2005. Studies on climatic change of last 40 years on Erdos Plateau. Journal of Desert Research, 25(6): 874-879. (in Chinese)

Rogers J C, Van Loon H. 1979. The seesaw in winter temperatures between Greenland and northern Europe. Part II: Some oceanic and atmospheric effects in middle and high latitudes. Monthly Weather Review, 107: 509-519.

Trenberth K E, Dai A, Rasmussen R M, et al. 2003. The changing character of precipitation. Bulletin of the American Meteorological Society, 84: 1205-1217.

Ursula G, Vahid N, Igor K, et al. 2013. The relationship between precipitation anomalies and satellite-derived vegetation activity in Central Asia. Global and Planetary Change, 110: 74-87.

Wang B, Bao Q, Hoskings B, et al. 2008. Tibetan Plateau warming and precipitation change in East Asia. Geophysical Research Letter, 35, L14702, doi: 10.1029/2008GL034330.

Wang H J, Chen Y N, Chen Z S. 2013a. Spatial distribution and temporal trends of mean precipitation and extremes in the arid region, northwest of China, during 1960-2010. Hydrological Processes, 27(12): $1807-1818$.

Wang S J, Zhang M J, Sun M P, et al. 2013b. Changes in precipitation extremes in alpine areas of the Chinese Tianshan Mountains, central Asia, 1961-2011. Quaternary International, 311: 97-107.

Wehrden V H, Hanspach J, Ronnenberg K, et al. 2010. Inter-annual rainfall variability in Central Asia: A contribution to the discussion on the importance of environmental stochasticity in drylands. Journal of Arid Environments, 74(10): 1212-1215.

Xu L G, Zhou H F, Liang C, et al. 2010. Spatial and temporal variability of annual and seasonal precipitation over the desert region of China during 1951-2005. Hydrological Processes, 24(20): 2947-2959.

Xu Z, Gong T, Li J. 2008. Decadal trend of climate in the Tibetan Plateau-regional temperature and precipitation. Hydrological Processes, 22(16): 3056-3065.

Yao J Q, Yang Q, Chen Y N, et al. 2013. Climate change in arid areas of Northwest China in past 50 years and its effects on the local ecological environment. Chinese Journal of Ecology, 32(5): 1283-1291. (in Chinese)

Yue S, Pilon P, Cavadias G. 2002. Power of the Mann-Kendall and Spearman's tests for detecting monotonic trends in hydrological series. Journal of Hydrology, 259: 254-271. 